\title{
Overexpression of a human potassium channel suppresses cardiac hyperexcitability in rabbit ventricular myocytes
}

\author{
H. Bradley Nuss, Eduardo Marbán, and David C. Johns
}

Section of Molecular and Cellular Cardiology, Department of Medicine, The Johns Hopkins University School of Medicine, Baltimore, Maryland 21205, USA

Address correspondence to: Eduardo Marbán, Section of Molecular and Cellular Cardiology, The Johns Hopkins University School of Medicine, 844 Ross Building, 720 N. Rutland Avenue, Baltimore, Maryland 21205, USA. Phone: (410) 955-2776; Fax: (410) 955-7953; E-mail: marban@welchlink.welch.jhu.edu

Received for publication August 31, 1998, and accepted in revised form February 9, 1999.

The high incidence of sudden death in heart failure may reflect abnormalities of repolarization and heightened susceptibility to arrhythmogenic early afterdepolarizations (EADs). We hypothesized that overexpression of the human $\mathrm{K}^{+}$channel HERG (human ether-a-go-go-related gene) could enhance repolarization and suppress EADs. Adult rabbit ventricular myocytes were maintained in primary culture, which suffices to prolong action potentials and predisposes to EADs. To achieve efficient gene transfer, we created AdHERG, a recombinant adenovirus containing the HERG gene driven by a Rous sarcoma virus (RSV) promoter. The virally expressed HERG current exhibited pharmacologic and kinetic properties like those of native $I_{\mathrm{Kr}}$. Transient outward currents in AdHERG-infected myocytes were similar in magnitude to those in control cells, while stimulated action potentials $\left(0.2 \mathrm{~Hz}, 37^{\circ} \mathrm{C}\right)$ were abbreviated compared with controls. The occurrence of EADs during a train of action potentials was reduced by more than fourfold, and the relative refractory period was increased in AdHERG-infected myocytes compared with control cells. Gene transfer of delayed rectifier potassium channels represents a novel and effective strategy to suppress arrhythmias caused by unstable repolarization.

J. Clin. Invest. 103:889-896 (1999).

\section{Introduction}

The delayed rectifier potassium current $\left(I_{\mathrm{K}}\right)$ is critical for normal repolarization in the heart. It represents the sum of two components that are kinetically, pharmacologically, and genetically distinct. The faster component, designated $I_{\mathrm{Kr}}$, is blocked selectively by class III antiarrhythmic drugs such as dofetilide, E-4031, dl-sotalol, and MK-499 (1). Putative genes have been identified for both components of $I_{\mathrm{K}}$ : the human ether-a-go-go-related gene $(H E R G)(2-4)$ encodes $I_{\mathrm{Kr}}$ channels, while $\operatorname{KvLQT1}(5,6)$ encodes the major subunit of the slower $\mathrm{I}_{\mathrm{Ks}}$ channels. Both $I_{\mathrm{Kr}}$ and $I_{\mathrm{Ks}}$ are regulated by an accessory protein encoded by the $\min K$ gene. When expressed heterologously, $\min K$ increases the number of functional channels at the cell-surface membrane and, at least in the case of $I_{\mathrm{Ks}}$, modifies the kinetics of the current to more closely mimic its endogenous counterpart (7).

Genetic and pharmacologic misfortunes have helped underscore the importance of HERG $/ I_{\mathrm{Kr}}$ for normal repolarization and suppression of lethal ventricular arrhythmias. Naturally occurring mutations in HERG, producing nonfunctional channels and reduced current, underlie the chromosome 7-linked form of long Q-T syndrome (8-12). Afflicted individuals demonstrate prolonged Q-T intervals and experience sporadic arrhythmias, placing them at risk for sudden cardiac death. Administration of seemingly benign noncardiac prescription drugs, such as the antihistamine terfenadine $(13,14)$ and the prokinetic agent cisapride $(15$, 16), have been responsible for the initiation of lethal arrhythmias. Both compounds are capable of prolonging the Q-T interval and inducing torsades de pointes in susceptible individuals through their potent blocking action on $I_{\mathrm{Kr}}(17,18)$.

To date, the role of $I_{\mathrm{Kr}}$ in repolarization has been probed only by using $I_{\mathrm{Kr}}$-specific blockers (19) and through various quantitative simulations (20-22). The primary goal of this study was to advance our understanding of the importance of $I_{\mathrm{Kr}}$ for normal cardiac repolarization and suppression of ventricular arrhythmias. The strategy was to determine the functional consequences of HERG overexpression on cardiac excitability through direct experimentation. HERG overexpression was achieved in adult rabbit ventricular myocytes in primary culture using adenovirally mediated gene transfer. Genetically increasing $H E R G$ current in myocytes shortens action potential duration, decreases susceptibility to early afterdepolarizations (EADs), and increases the refractory period.

\section{Methods}

Isolation and primary culture of rabbit ventricular myocytes. Rodshaped myocytes were isolated from the left ventricles of normal rabbits via enzymatic digestion of the whole heart on a Langendorff apparatus, using common cell isolation techniques (23). Animals were euthanized by pentobarbital overdose $(80 \mathrm{mg} / \mathrm{kg}$ intravenously). Hearts were rapidly excised and rinsed in a modified Tyrode's solution and then mounted on a Langendorff apparatus. The coronaries were perfused retrogradely with the following four solutions in sequential order: $1 \mathrm{mM}$ Ca Tyrode's ( 2 min), Ca-free Tyrode's (6.5 min), Ca-free Tyrode's containing collagenase (Worthington type IV) and protease (Sigma Chemical Co., St. Louis, Missouri, USA) ( $8 \mathrm{~min})$, and $0.1 \mathrm{mM} \mathrm{Ca}$ Tyrode's ( $2 \mathrm{~min})$. When the heart tissue became flaccid, the left ventricle was dissected free and mechanically dissociated to release individual myocytes. The freshly isolated myocytes were 
gently centrifuged and resuspended in standard culture medium: Medium M199 with Earl's salts and L-glutamine (Cellgro; Mediatech Inc., Herndon, Virginia, USA), supplemented with penicillin (PCN-K+ $50 \mathrm{U} / \mathrm{ml}$; Sigma Chemical Co.) and $2 \%$ FBS (HyClone Laboratories, Logan, Utah, USA). Myocytes were suspended to a final concentration of $5 \times 10^{4}$ cells $/ \mathrm{ml}$ and plated onto laminin-coated coverslips $(20 \mu \mathrm{l} / \mathrm{ml}$; Sigma Chemical Co.). Cells were maintained at $37^{\circ} \mathrm{C}$ in a humidified atmosphere of $5 \% \mathrm{CO}_{2}$ and $95 \%$ air.

Adenovirus vector construction. The HERG adenovirus vector was engineered and constructed following established methods (24). Briefly, the full-length coding sequence of the HERG potassium channel (2-4) (provided by M. Keating, University of Utah, Salt Lake City, Utah, USA) was subcloned into our adenoviral shuttle vector (pEIRSV) (24). The bacterial plasmid pJM17, incorporating the full-length adenovirus 5 genome and the plasmid shuttle vector containing the HERG insert, was cotransfected into HEK 293 cells. Homologous recombination between PJM17 and the shuttle vector resulted in a replicationdeficient recombinant adenovirus (AdHERG), with the HERG gene insert replacing the native viral early region 1 between map units 1.0 and 9.8. A control reporter adenovirus (AdGFP) was constructed that encodes the mitochondrially targeted green fluorescent protein (25) with the S65T point mutation for enhanced fluorescence (26).

Infection of myocytes. As described previously (27), ventricular myocytes isolated and maintained in primary culture for 12-18 $\mathrm{h}$ were infected (5-20 moi) with AdHERG and AdGFP, AdGFP alone, or left noninfected. Expression of the virally transduced HERG currents began to appear above the background native currents within $24 \mathrm{~h}$ after infection and further increased in size by $48 \mathrm{~h}$.

Electrophysiology. All electrical recordings were made 36-72 h after the isolation of the myocytes using standard whole-cell voltage clamp recording methods (28). Pipettes had tip resistances of 2-4 M $\Omega$ when filled with a solution comprised of: 125 $\mathrm{mM}$ K-glutamate, $15 \mathrm{mM} \mathrm{KCl}, 5 \mathrm{mM} \mathrm{NaCl}, 1 \mathrm{mM} \mathrm{MgCl} 2,4$ mM MgATP, and $10 \mathrm{mM}$ HEPES, with $\mathrm{pH}$ adjusted to 7.3 with $\mathrm{KOH}$. The modified Tyrode's recording solution used in these experiments was comprised of: $135 \mathrm{mM} \mathrm{NaCl}, 4 \mathrm{mM} \mathrm{KCl}, 1$ $\mathrm{mM} \mathrm{MgCl} 2,10 \mathrm{mM}$ dextrose, $10 \mathrm{mM}$ HEPES, and $2 \mathrm{mM} \mathrm{CaCl}_{2}$, with $\mathrm{pH}$ adjusted to 7.3 with $\mathrm{NaOH}$. In some experiments, the methanesulfonanilide class III antiarrhythmic agent E-4031 (Eisai Co., Tokyo, Japan) was used to selectively block HERG $/ I_{\mathrm{Kr}}$ current (1). All experiments were performed at body tempera-

a

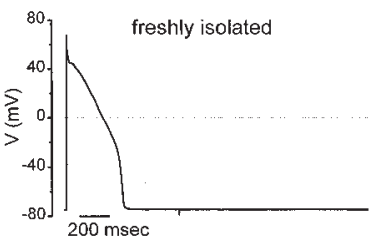

$\boldsymbol{b}$

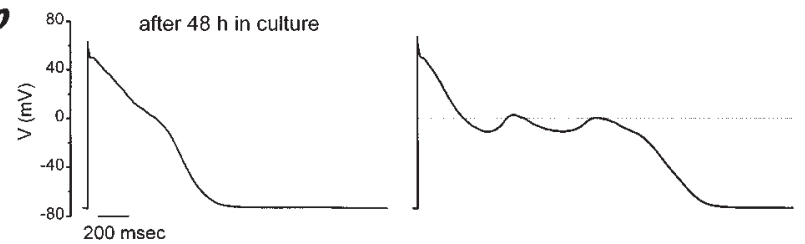

Figure 1

Electrical recordings on isolated myocytes at $37^{\circ} \mathrm{C}$ indicate that compared with freshly isolated myocytes ( $\boldsymbol{a}$ ) AP repolarization is delayed in rabbit ventricular myocytes maintained in primary culture for $48 \mathrm{~h}(\boldsymbol{b})$. Cultured myocytes also exhibited frequent early afterdepolarizations $(b$, right $)$ that were not observed normally in freshly isolated myocytes. $A P$, action potential. ture $\left(37^{\circ} \mathrm{C}\right)$ to characterize the electrophysiology of the cloned channels under physiologic conditions. Macroscopic current-voltage relations were measured from depolarizing voltage steps $(500 \mathrm{~ms}$ ) to potentials between $-70 \mathrm{mV}$ and $+60 \mathrm{mV}$ from a holding potential of $-80 \mathrm{mV}$. The voltage dependence of activation was determined from tail currents measured upon repolarization to $-100 \mathrm{mV}$.

Statistical analysis. Pooled data are presented as means \pm SE. Comparison of measurements between groups were performed using a Student's $t$ test. Differences in the data were considered statistically significant when $P<0.05$.

\section{Results}

The overriding goal of this study was to test the hypothesis that the expression level of $H E R G / I_{\mathrm{Kr}}$ dictates the repolarization properties and susceptibility to EADs of ventricular myocytes. We have previously demonstrated the utility of adenoviral gene transfer for introducing a foreign potassium channel gene (Drosophila Shaker B) into living heart cells in culture (27). We have now used the same approach to probe the physiologic consequences of overexpression of $I_{\mathrm{Kr}}$ using adenovirally mediated gene transfer of HERG.

Prolonged action potentials and susceptibility to EADs in cultured myocytes. Similar to the development of electrophysiologic alterations in heart failure, the expression levels and/or function of specific ion channels also change when adult ventricular myocytes are maintained in culture. After several days in primary culture, rabbit ventricular myocytes exhibit a decreased level of expression of potassium currents that govern repolarization (29). The changes in ionic currents may be related to abnormal turnover of these membrane ion channels in a nonphysiological neural and hormonal environment.

Action potentials (APs) in myocytes isolated from the left ventricle of the rabbit and maintained in primary culture for 48 hours (Fig. 1b) are noticeably prolonged compared with APs recorded in freshly isolated myocytes (Fig. 1a). Additionally, we observed an increased susceptibility to EADs in the cultured myocytes (Fig. 1b). Both phenomena are likely due to the general downregulation of potassium channels that occurs in culture (29).

Phenotype of adenovirally expressed HERG current. $I_{\mathrm{Kr}}$ is important for repolarization in the heart in a number of species, including humans. In addition to the genetic evidence for its role in long Q-T syndrome, $I_{\mathrm{Kr}}$-specific blockers are known to prolong ventricular AP (1, $30,31)$ and facilitate EADs $(32,33)$. It is likely that $H E R G$ encodes the primary component of $I_{\mathrm{Kr}}$ channels as a heterologous expression of HERG in conventional expression systems, which otherwise lack appreciable membrane currents, resulting in currents very similar but not identical to $I_{\mathrm{Kr}}(34)$. As shown in Fig. 2, robust HERG currents were recorded in AdHERG-infected Chinese hamster ovary $(\mathrm{CHO})$ cells. Noninfected $\mathrm{CHO}$ cells lack any appreciable endogenous currents (not shown). At room temperature, the kinetics of activation during depolarization are slow, while the large tail currents elicited upon repolarization to hyperpolarized potentials demonstrate rapid recovery of HERG channels from fast inactivation and subsequent deactivation. The average peak outward HERG current density measured by a voltage step to $+20 \mathrm{mV}$ equaled $5.2 \pm 1.4$ 


\section{Figure 2}

Virally transduced HERG current in $\mathrm{CHO}-\mathrm{K} 1$ cells. Wholecell currents recorded at $22^{\circ} \mathrm{C}$ in CHO-K1 cells $36 \mathrm{~h}$ after infection with AdHERG. Currents recorded by families of step depolarizations on pulse $1(\boldsymbol{a})$ and pulse $2(\boldsymbol{b})$ demonstrate the characteristic behavior of HERG current. Increasing the size of the depolarizing voltage step speeds activation and causes rectification of HERG current (a). Changing the repolarization potential following a step to $+20 \mathrm{mV}$ demonstrates recovery from inactivation of channels at hyperpolarized voltages as well as reversal of HERG current near the $\mathrm{K}^{+}$equilibrium potential (b). (c) Summary data indicate the average density of the outward current at $+20 \mathrm{mV}$ during pulse 1 (open bar) and inward current upon repolarization to $-100 \mathrm{mV}$ ( filled bar, $n=6$ ).
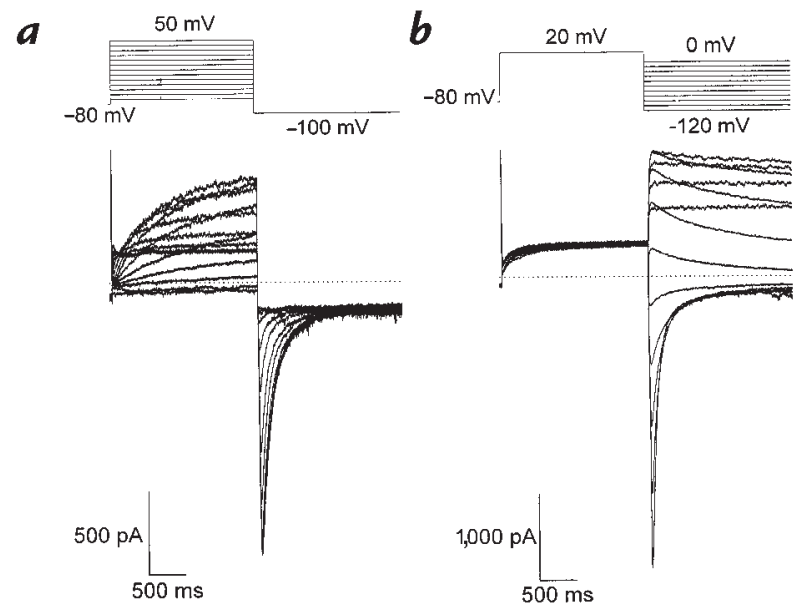

$\boldsymbol{c}$

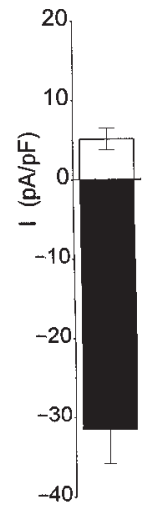

$\mathrm{pA} / \mathrm{pF}$ (Fig. $2 c$, open bar; $n=6$ ). Inward tail currents elicited upon immediate repolarization to $-100 \mathrm{mV}$ equaled $-31.5 \pm 4.3 \mathrm{pA} / \mathrm{pF}$ (Fig. $2 c$, filled bar; $n=6$ ).

The virally expressed HERG channels behave identically to native $I_{\mathrm{Kr}}$ (Fig. 3), exhibiting modulation by extracellular $\mathrm{K}^{+}$concentration (35-37), and block by the methanesulfonanilide class III antiarrhythmic agent E$4031(38,39)$ and the trivalent cation lanthanum $(35)$. As shown in Fig. $3 a$, increasing $\mathrm{K}^{+}$concentration in the recording solution from $4 \mathrm{mM}$ to $8 \mathrm{mM}$ increased HERG current amplitude and slowed the decay of the tail currents upon repolarization. In AdHERG-infected cardiac myocytes, the contribution of $H E R G$ current to the net membrane current elicited by a slow voltage ramp is revealed after exposure to E-4031 (5 $\mu \mathrm{M}$; Fig. $3 b)(1)$ or lanthanum (10 $\mu \mathrm{M}$; Fig. $3 c)$.

HERG overexpression increases maintained outward current. Activation of HERG current in a cardiac background is more difficult to distinguish than in CHO-K1 cells, because the calcium-independent transient outward $\mathrm{K}^{+}$ current $\left(I_{\mathrm{to} 1}\right)$ activates rapidly and overlaps with HERG at positive potentials. Figure 4 shows examples of the baseline currents in rabbit ventricular myocytes in culture and in an AdHERG-infected cell upon depolarization to +20 $\mathrm{mV}$ (Fig. 4, $a$ and $b$ ) or $+60 \mathrm{mV}$ (Fig. 4, $d$ and $e$ ). A prominent $I_{\mathrm{to} 1}$ and $I_{\mathrm{Na}}$ appear in both noninfected and AdHERG-infected cells. At 36-48 hours after infection the level of sustained current elicited by a voltage step to $+20 \mathrm{mV}$ (500 ms) in AdHERG-infected myocytes (5.3 \pm $2.1 \mathrm{pA} / \mathrm{pF} ; n=10)$ is more than fivefold greater $(P<0.05)$ than in noninfected or AdGFP-infected myocytes (0.8 \pm $0.3 \mathrm{pA} / \mathrm{pF} ; n=9$ ) (Fig. $4 c$ ). In tail current measurements, the half activation potential for $I_{\mathrm{Kr}}$ in AdHERG-infected rabbit ventricular myocytes equaled $5 \pm 1 \mathrm{mV}(n=10)$. Activation of HERG current was similar to the activation of $I_{\mathrm{Kr}}$ in noninfected and AdGFP-infected myocytes ( $3 \pm$

\section{Figure 3}

Modulation of virally expressed HERG current by extracellular $\mathrm{K}^{+}(\boldsymbol{a})$ and block by E-4031 ( $\left.\boldsymbol{b}\right)$ or lanthanum $(\boldsymbol{c})$. (a) Increasing extracellular $\mathrm{K}^{+}$from $4 \mathrm{mM}$ to $8 \mathrm{mM}$ increased the magnitude of HERG current recorded in AdHERGinfected myocytes (1 and 2; 2-s depolarizations) and slowed the decay of HERG tail current elicited upon repolarization to -100 $\mathrm{mV}$ (1 and 3). Net membrane current recorded in response to a voltage ramp $(+60 \mathrm{mV}$ to $-120 \mathrm{mV}, 2 \mathrm{~s}$ ) exhibits outward HERG current that is blocked by $5 \mu \mathrm{M} \mathrm{E}-4031$ (b) or $10 \mu \mathrm{M}$ lanthanum (c). $\mathrm{CHO}$, Chinese hamster ovary.

$a$
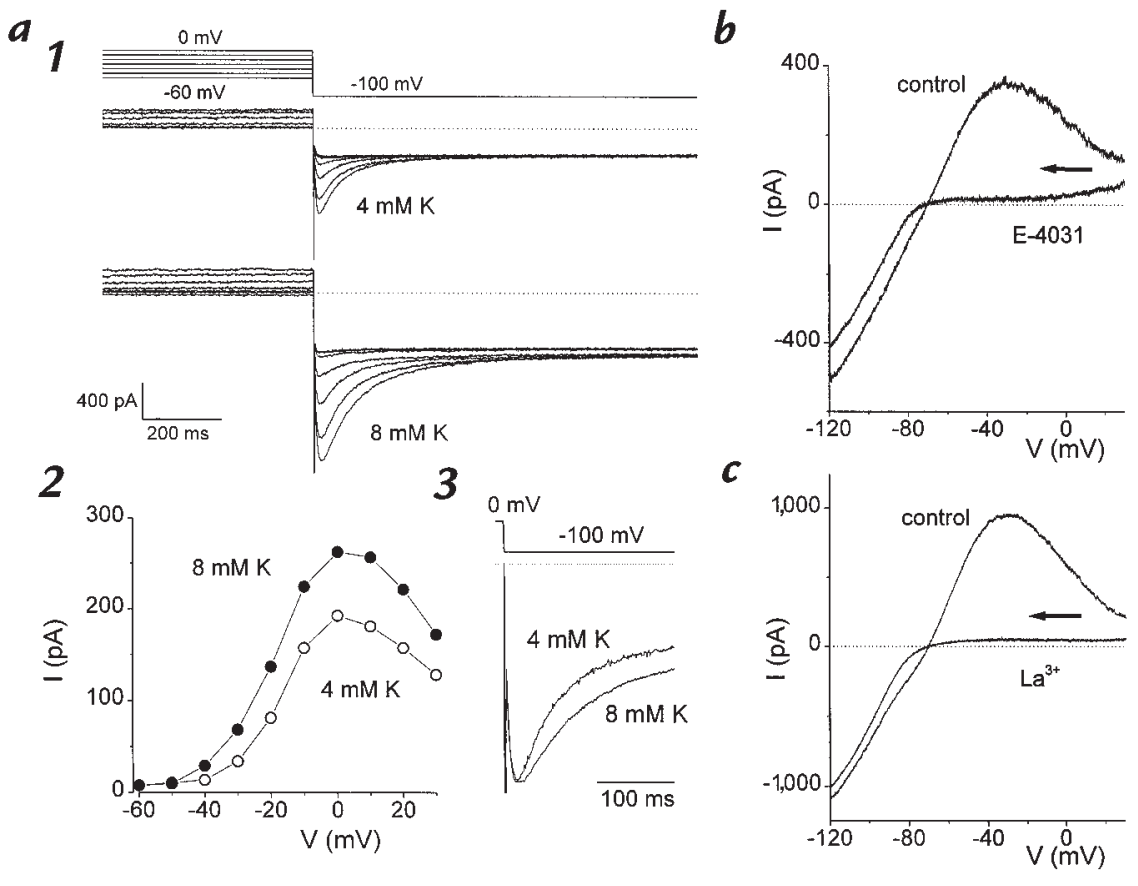
$4 \mathrm{mV} ; n=9)$. The steady-state current-voltage relationships measured at $500 \mathrm{~ms}$ by a step depolarization in noninfected and AdGFP-infected cells show predominately the level of sustained $I_{\text {to1 }}$ current primarily at potentials beyond $0 \mathrm{mV}$. In AdHERG-infected cells, activation of HERG current begins at $-10 \mathrm{mV}$ and then dominates the $I-V$ relationship at positive voltages. The magnitude of sustained current is largest at $+20 \mathrm{mV}$ with the characteristic rectification of HERG (and $I_{\mathrm{Kr}}$ ) current decreasing the sustained current at $+30 \mathrm{mV}$ and beyond.

Expression in cardiac cells accelerates the decay of HERG tail current. The kinetics of HERG current expressed in cardiac myocytes more closely resembles endogenous $I_{\mathrm{Kr}}$ than recordings of $H E R G$ expressed in mammalian cell lines. A direct comparison of the HERG current recordings obtained in $\mathrm{CHO}-\mathrm{K} 1$ cells at $22^{\circ} \mathrm{C}$ (Fig. $2 b$ ) to those in rabbit ventricular myocytes at $37^{\circ} \mathrm{C}$ (Fig. 4, $b$ and $e$ ) suggested that the increased temperature and/or expression in ventricular myocytes accelerates decay of the tail currents. Inward HERG tail currents were examined in detail by fitting a single exponential decay function to the tail current recorded upon repolarization to -100 $\mathrm{mV}$ following depolarization to $-20 \mathrm{mV}$. Tail current kinetics were compared for HERG channels expressed in $\mathrm{CHO}-\mathrm{K} 1$ cells at room temperature, cardiac myocytes at room temperature, and cardiac myocytes at body temperature. The results indicate that expression in a cardiac background accelerated the decay of HERG tail current independent of temperature: the time constant of decay equaled $211 \pm 48 \mathrm{~ms}$ in CHO-K1cells at $22^{\circ} \mathrm{C}(n=6)$ versus $116 \pm 18 \mathrm{~ms}$ in myocytes at $22^{\circ} \mathrm{C}(n=9, P=0.04)$. For $H E R G$ channels expressed in cardiac myocytes, increasing the temperature to $37^{\circ} \mathrm{C}$ additionally accelerated the decay of the tail currents to $9 \pm 1 \mathrm{~ms}(n=10, P<0.01)$.

Selective overexpression of HERG. Adult rabbit ventricular myocytes infected with the HERG adenovirus exhibit selective overexpression of HERG current without net effects on the expression of other $\mathrm{K}^{+}$channels. The magnitude of the early peak outward current in noninfected and AdGFPinfected control cells, which is largely contributed by $I_{\text {to1 }}$ and has been shown to be reduced in heart failure (40), is similar in amplitude to that in AdHERG-overexpressing cells (Fig. 4, $d$ and $e$ ). Comparison of the peak early outward current elicited upon depolarization to $+60 \mathrm{mV}$ in noninfected cells and cells infected with AdGFP (17.6 \pm 2.3 $\mathrm{pA} / \mathrm{pF} ; n=9)$, to those measured in AdHERG-infected cells $(14.7 \pm 3.0 \mathrm{pA} / \mathrm{pF} ; n=10)$, indicates that the endogenous early outward $\mathrm{K}^{+}$current is not significantly altered by AdHERG infection (Fig. 4f). The peak early current-voltage relationships measured between $-70 \mathrm{mV}$ and $+60 \mathrm{mV}$
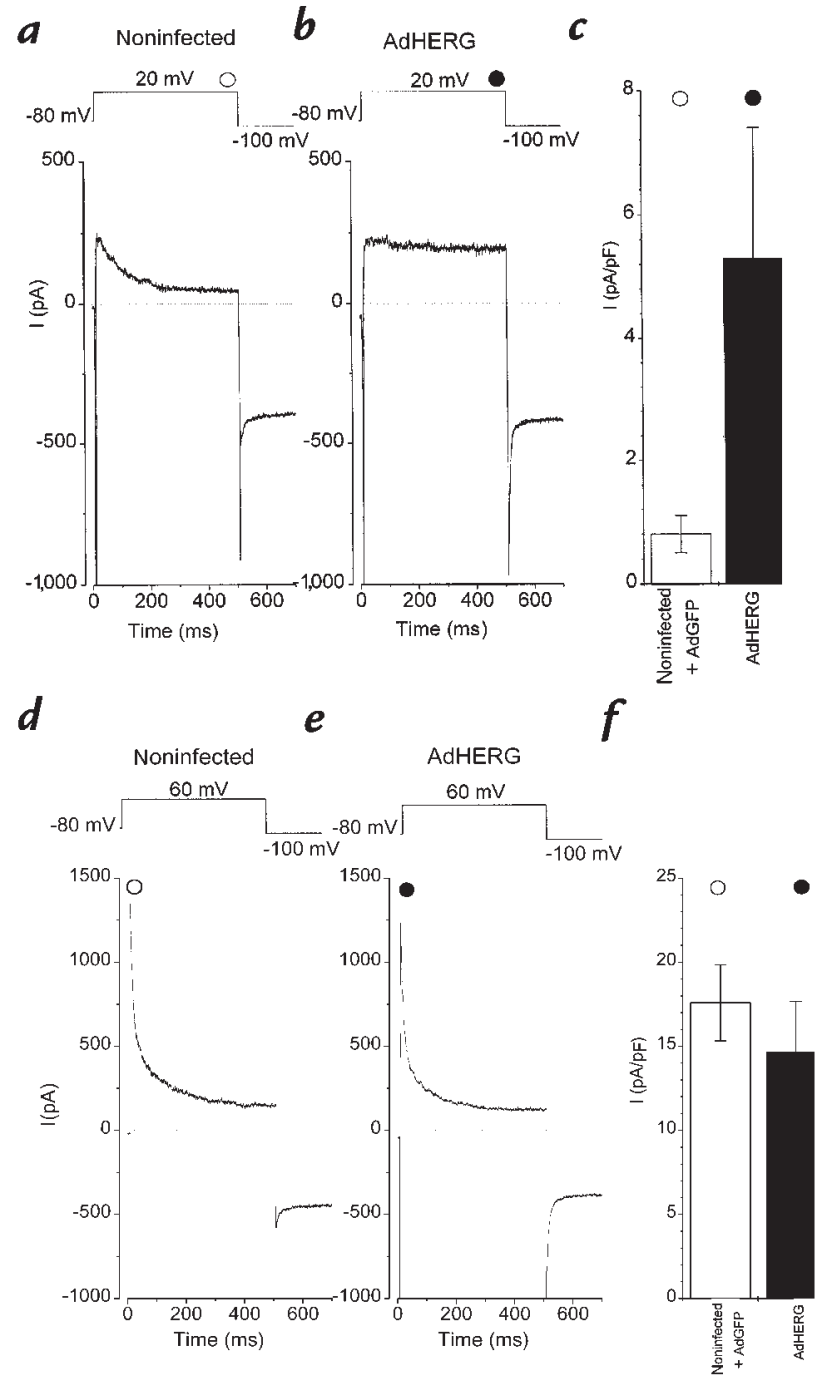

\section{Figure 4}

Maintained outward current at $+20 \mathrm{mV}$ is increased, and transient outward $\mathrm{K}^{+}$current is unchanged in AdHERG-infected myocytes. (a) Membrane currents elicited by a voltage step to $+20 \mathrm{mV}$ in noninfected and AdGFP-infected rabbit ventricular myocytes exhibit the characteristic $/_{\mathrm{Na}}$ spike followed by a large $I_{\text {to1 }}$. (b) The decay of $I_{\text {to } 1}$ is masked by the sustained level of HERG current in HERG-overexpressing myocytes. (c) On average, the level of sustained current was increased fivefold in AdHERG-infected myocytes (filled bar, $n=9$ ) compared with controls (open bar, $n=10$ ). Membrane current recordings obtained at $+60 \mathrm{mV}$ show the rapid activation and inactivation of $I_{\text {to } 1}$ in noninfected and AdGFP-infected $(\boldsymbol{d})$ and AdHERG-infected myocytes $(\boldsymbol{e})$. The decay of current in AdHERG-infected myocytes is similar to that in controls because of the strong rectification of HERG current at positive potentials. $(\boldsymbol{f})$ Average peak $I_{\text {to1 }}$ current density was not significantly altered in AdHERGinfected myocytes $(n=9)$ compared with controls (open bar, $n=10$ ). 


\section{Figure 5}

(a) Block of HERG current by the $I_{\mathrm{Kr}}$-specific blocker E-4031 was assessed from the amplitude of the peak outward tail current elicited upon repolarization to -40 $\mathrm{mV}$ in AdHERG-infected rabbit ventricular myocytes. (b) The $\mathrm{IC}_{50}$ for steady-state E-4031 block of HERG expressed in myocytes equals $123 \pm 11 \mathrm{nM}$ $(n=12)$. (c) Based on tail current measurements, the E-4031-sensitive current $(1-3 \mu \mathrm{M})$ is 10 -fold larger in AdHERG-infected myocytes (filled bar, $n=17$ ) compared with controls (open bar, $n=7$ ).

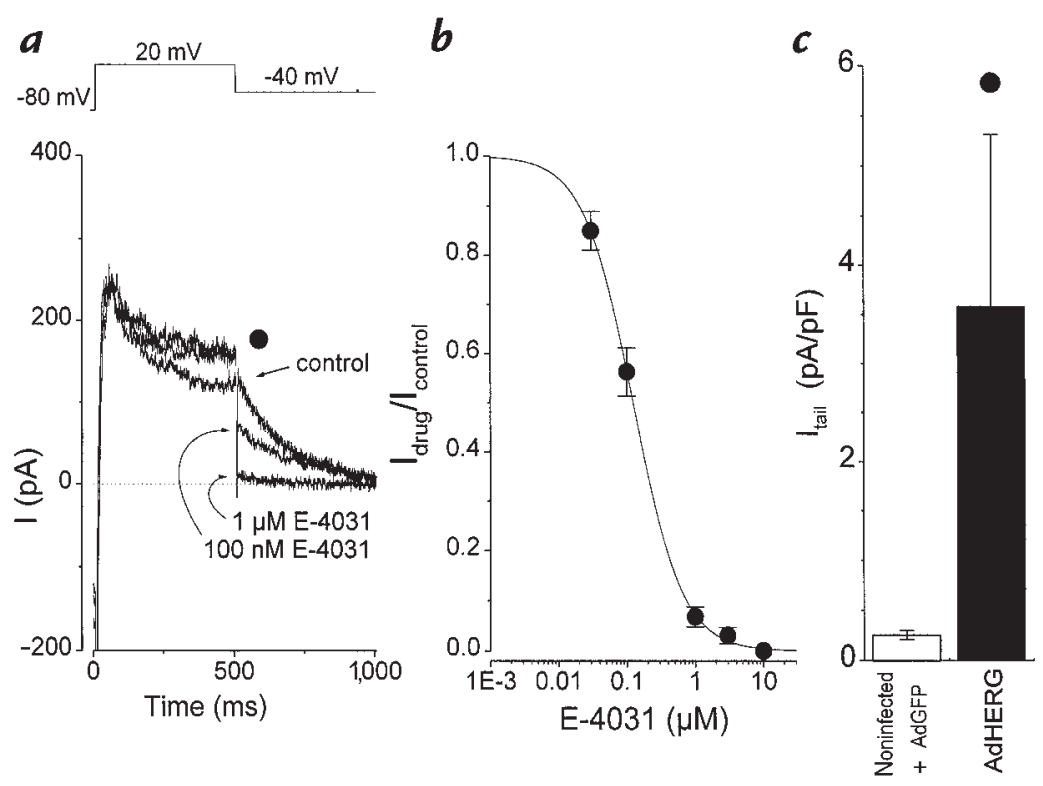

for noninfected, AdGFP-infected, and AdHERG-infected myocytes have similar shapes and current densities over the range of potentials tested (not shown).

Sensitivity of HERG to block by E-4031. The virally expressed HERG current is effectively blocked by E-4031, a potent blocker of endogenous $I_{\mathrm{Kr}}$ current (1) (Fig. 5). We assessed steady-state block by measuring the peak outward tail current elicited upon repolarization to -40 $\mathrm{mV}$ after a 500 millisecond step to $+20 \mathrm{mV}$ (Fig. 5a). Based on these tail current measurements, E-4031 exhibited an $\mathrm{IC}_{50}$ of $123 \pm 11 \mathrm{nM}(n=12)$ for block of HERG current expressed in cardiac myocytes (Fig. $5 b$ ). The sensitivity of HERG channels overexpressed in rabbit ventricular cells to block by E-4031 compares favorably to published $\mathrm{IC}_{50}$ values for block of native $I_{\mathrm{Kr}}$ current in guinea pig and ferret cardiac myocytes $(1,41)$. At these low concentrations, E-4031 is selective for $I_{\mathrm{Kr}}(1,42)$ and exogenously expressed HERG current (39). The summary data in Figure $5 c$ compares the magnitude of the E-4031-sensitive tail currents (1-3 $\mu \mathrm{M}$ E-4031) in AdHERG-infected cells $(3.6 \pm 1.7 \mathrm{pA} / \mathrm{pF} ; n=17)$ to that in noninfected and AdGFP-infected control cells ( $0.3 \pm$ $0.1 \mathrm{pA} / \mathrm{pF} ; n=7)$. HERG overexpression induced a $10-$ fold increase in the E-4031-sensitive current in AdHERG-infected myocytes compared with controls.

Effects of HERG overexpression on repolarization. The effects of $H E R G$ overexpression on cardiac excitability were examined by stimulating APs in rabbit ventricular myocytes with varying levels of expression of HERG current. We found that HERG overexpression abbreviated the rabbit ventricular AP without adversely modifying the normal AP waveform. As shown in Figure 6a, APs stimulated at $0.2 \mathrm{~Hz}$ were shortened significantly $(P<$ 0.01 ) by HERG overexpression. The summary data (Fig. $6 b)$ compare AP duration at $90 \%$ repolarization $\left(\mathrm{APD}_{90}\right)$ in AdHERG-infected cells $(195 \pm 60 \mathrm{~ms} ; n=18)$ with noninfected and AdGFP-infected control cells $(672 \pm 132 \mathrm{~ms}$; $n=12) ; \mathrm{APD}_{90}$ is shortened by $70 \%$ on average by HERG overexpression. In fact, we observed that APs are abbreviated as a function of the level of HERG current overex- pression. In Fig. $6 c$, linear regression analysis shows a positive correlation $(P<0.02)$ between $\mathrm{APD}_{90}$ and the level of current in AdHERG-infected cells (filled circles; $n=17$ ). The current-voltage relationships recorded in this manner have a prominent $\mathrm{N}$ shape in AdHERGinfected cells. Although the correlation between APD $_{90}$ and current density in noninfected and control myocytes (Fig. $6 c$, open squares; $n=12$ ) did not attain significance $(P=0.10)$, it did indicate the maximal effect of $H E R G$ overexpression on abbreviating the AP, which is borne out in the AdHERG-infected data.

Effects of HERG overexpression on susceptibility to EADs. Alterations in $\mathrm{K}^{+}$current expression, regardless of the cause, have a profound impact on repolarization and susceptibility to EADs. The increased susceptibility to EADs in failing canine ventricular myocytes is associated with the downregulation of $I_{\mathrm{to} 1}$ and $I_{\mathrm{K} 1}$ that occurs from chronic tachycardia pacing (43). We examined whether the changes in $\mathrm{K}^{+}$current expression that occur in rabbit cardiac myocytes over time in culture would make repolarization unstable. The short segments of APs shown in Figure 7 illustrate that during continuous stimulation the incidence of EADs in noninfected myocytes maintained in primary culture was high and that phase 2 EADs often recurred during the same AP. After the initiation of an $\mathrm{EAD}$, the $\mathrm{AP}$ waveform became complex, with an unstable plateau between $-20 \mathrm{mV}$ and +10 $\mathrm{mV}$. APs recorded under identical conditions in HERG-overexpressing myocytes rarely exhibited EADs. The frequency of EADs in noninfected and AdGFP-infected control cells $(0.40 \pm 0.17$ EADs/AP; $n=7)$ was reduced fivefold by HERG overexpression (0.09 $\pm 0.05 \mathrm{EADs} / \mathrm{AP} ; n=12, P<0.05)$. Repolarization in AdHERG-infected cells appears normal and these APs more closely resemble APs recorded in freshly isolated myocytes. The summary data indicate how effectively HERG overexpression suppresses EADs. Overexpression of HERG in cultured canine ventricular myocytes had similar effects: abbreviation of APs and suppression of EADs $(n=13$, data not shown).

Effects of HERG overexpression on the refractory period. We were motivated to examine the effect of HERG overex- 
pression on the effective refractory period (ERP) because we observed afterhyperpolarizations in cells with high levels of HERG current and because nicorandil, a $\mathrm{K}^{+}$channel opener, provides increased protection against premature stimuli in long Q-T syndrome patients by prolonging the ERP (44). It has also been suggested that HERG may guard against premature beats because of its unique gating properties (45). Currents that figure prominently in determining the ERP have important implications in determining the recovery of excitability in the ventricle. To establish whether the level of expression of HERG $\mathrm{K}^{+}$channels helps determine the refractory period in myocytes, APs were stimulated at a constant rate $(0.5 \mathrm{~Hz})$, and a premature suprathreshold stimulus (115\% of threshold) was interposed at varying intervals during a period of continuous stimulation. The coupling interval of the extrastimulus was increased until a premature AP was evoked.

The ERP is defined as the longest coupling interval that fails to evoke an AP. However, to distinguish changes in APD from changes in ERP, the relative refractory period (RRP) was measured from the $\mathrm{APD}_{90}$ of the first AP to the time of the premature stimulus that elicits a second AP. As defined, changes in refractory period are compared between control and AdHERG-infected cells independent of the APD shortening that occurs via $H E R G$ overexpression.

In AdGFP-infected cells, a second AP with a normal waveform could be elicited almost immediately upon repolarization to resting potential (Fig. 8). In contrast, in the AdHERG-infected cells, there is an obvious refractory period after final repolarization is completed. Based on these measurements, the RRP increased $82 \%$ in $H E R G$-overexpressing cells $(32 \pm 1 \mathrm{~ms} ; n=3)$ compared

\section{Figure 6}

HERG overexpression abbreviates APD. (a) Early (phase 2) and late (phase 3 ) repolarization is enhanced in AdHERG-infected myocytes compared with noninfected and AdGFP-infected control cells. (b) APD measured at $90 \%$ repolarization was shortened by $70 \%$ on average by HERG overexpression (filled bar) compared with controls (open bar). (c) Regression analysis indicates a positive correlation $(P<0.02)$ between APD and the magnitude of current recorded at $0 \mathrm{mV}$ by voltage ramp $(+60 \mathrm{mV}$ to $-120 \mathrm{mV}, 1 \mathrm{~s}$ ) in AdHERG-infected myocytes (filled circles; $n=17$ ). Regression analysis of data collected in noninfected and AdGFP-infected myocytes (open squares; $n=12$ ) did not correlate significantly $(P=0.10)$. $A P D$, action potential duration. with controls ( $18 \pm 3 \mathrm{~ms} ; n=4, P=0.02)$. Changes in the RRP associated with levels of HERG channel expression may suggest novel cellular and molecular mechanisms by which to manipulate refractoriness.

In summary, infection of adult rabbit ventricular myocytes with AdHERG produces selective enhancement of the E-4031-sensitive current. HERG overexpression abbreviates APs stimulated under physiologic conditions, and the degree of shortening correlates directly with the level of overexpression. In addition, EADs that are prevalent in cultured adult myocytes are suppressed by HERG overexpression and the refractory period is increased.

\section{Discussion}

We have introduced and overexpressed HERG in adult rabbit ventricular myocytes with the aim of determining the role that $H E R G / I_{\mathrm{Kr}}$ plays in repolarization and suppression of EADs. The experimental approach was to create and use an adenoviral construct and to introduce HERG into adult cardiac myocytes. Rabbit myocytes were ideally suited for the purposes of this study because many of the electrophysiologic and pharmacologic properties of the endogenous currents have been characterized, including $I_{\mathrm{Kr}}$ and $I_{\mathrm{Ks}}(46-48)$. In addition, adult ventricular myocytes are easily maintained in short-term primary culture and infected with adenoviral constructs containing ion channel coding sequences with high efficiencies (27).

Infection with AdHERG selectively enhanced the E4031-sensitive current without affecting the density of $I_{\text {to1 }}$. APs were abbreviated by more than 50\% in HERG- overexpressing myocytes without obvious modification of the normal AP waveform. HERG overexpression in normal rabbit myocytes, which demonstrate frequent EADs when

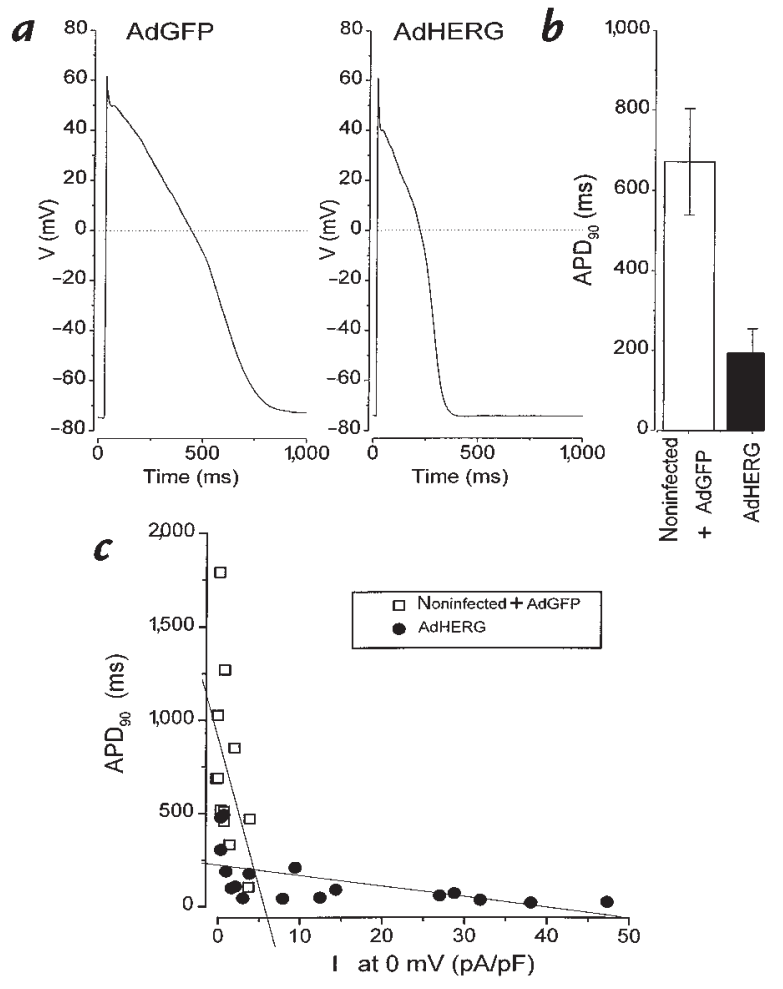


maintained in culture, effectively suppressed EADs and lengthened the refractory period. These results underscore the important role that $H E R G / I_{\mathrm{Kr}}$ normally plays in cardiac excitability and how inherited HERG channel dysfunction can predispose to lethal cardiac arrhythmias.

Associations with $\beta$ subunits or posttranslational modification unique to cardiac myocytes. The anomalously slow kinetics of HERG current when expressed in mammalian cells or oocytes (35) indicates that HERG alone, as the $\alpha$ subunit encoding $I_{\mathrm{Kr}}$, does not accurately reproduce native $I_{\mathrm{Kr}}$. We have found that HERG current kinetics are accelerated to normal values when expressed in cardiac myocytes, implicating potential associations of HERG with auxiliary $\beta$ subunits, perhaps including $\min K(49)$, or posttranslational modifications of HERG unique to cardiac myocytes. Additionally, we have confirmed that the effect of physiologic temperature on HERG expressed in cardiac myocytes (this study) is similar to that reported for HERG expressed in HEK 293 cells (39): HERG gating kinetics are accelerated and more closely resemble endogenous $I_{\mathrm{Kr}}$ at physiologic temperatures.

The role of $H E R G / I_{K r}$ current in repolarization. Zhou et al. (39) examined the role of HERG in AP repolarization experimentally by voltage clamping HERGexpressing HEK 293 cells and using a ventricular AP waveform as the command voltage. From these AP clamp experiments, Zhou et al. (39) found that HERG current activates rapidly following the upstroke of the $\mathrm{AP}$, increases during repolarization, reaches a maximum during phases 2 and 3 of the AP, and continues to contribute outward current even after membrane voltage returns to resting potential. This behavior of $H E R G / I_{\mathrm{Kr}}$ current during repolarization is unique to cardiac potassium channels and results from their unusual gating behavior - rapid recovery from inactivation and slow deactivation of the channels. This may explain why adenovirally mediated HERG overexpression so effectively suppressed the phase 2 EADs common to cultured adult cardiac myocytes while increasing the refractory period.

Viral gene transfer: bridging the gap between molecular biology and electrophysiology. This study proves that viral gene transfer can be used as an interventional approach to establish whether a particular abnormality reproduces all or part of the electrical phenotype of failing heart cells. Heart failure studies typically fall into one of two catagories: electrophysiologic studies that identify alterations in cellular currents, and molecular studies that report changes in expression of a given channel gene. To strengthen the etiologic links between the molecular and electrophysiologic alterations, we sought experimental evidence for causeand-effect relations between changes in $H E R G / I_{\mathrm{Kr}}$ expression and electrophysiologic abnormalities common in heart failure. We took an interventional genetic approach to manipulate the level of expression of $H E R G$ and characterized the electrophysiologic consequences of such overexpression. Our findings substantiate the notion that $H E R G / I_{\mathrm{Kr}}$ current is an important current for normal repolarization, helping to prevent initiation of arrhythmia and playing a role in establishing the refractory period.

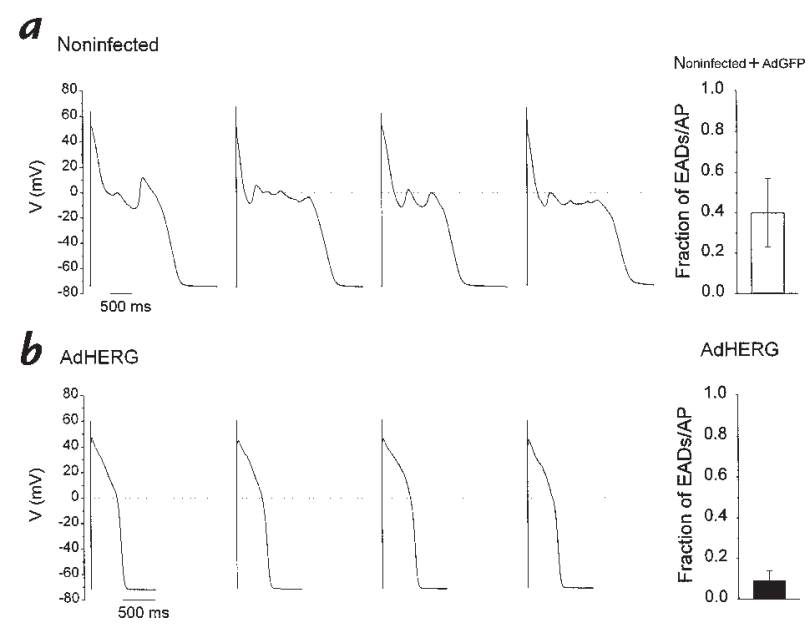

Figure 7

HERG overexpression suppresses EADs. (a) Noninfected and AdGFPinfected myocytes $(n=7)$ exhibit frequent and complex EADs during trains of continuously stimulated APs $\left(0.2 \mathrm{~Hz}\right.$. $\left.37^{\circ} \mathrm{C}\right)$. (b) In contrast, APs stimulated in AdHERG-infected myocytes $(n=12)$ repolarize normally. The summary data indicate the ratio of APs with an EAD (or multiple EADs) to the total number of APs in a stimulus train comprised of at least $10 \mathrm{APs}$. HERG overexpression significantly reduced the frequency of EADs $(P<0.05)$. EADs, early afterdepolarizations.

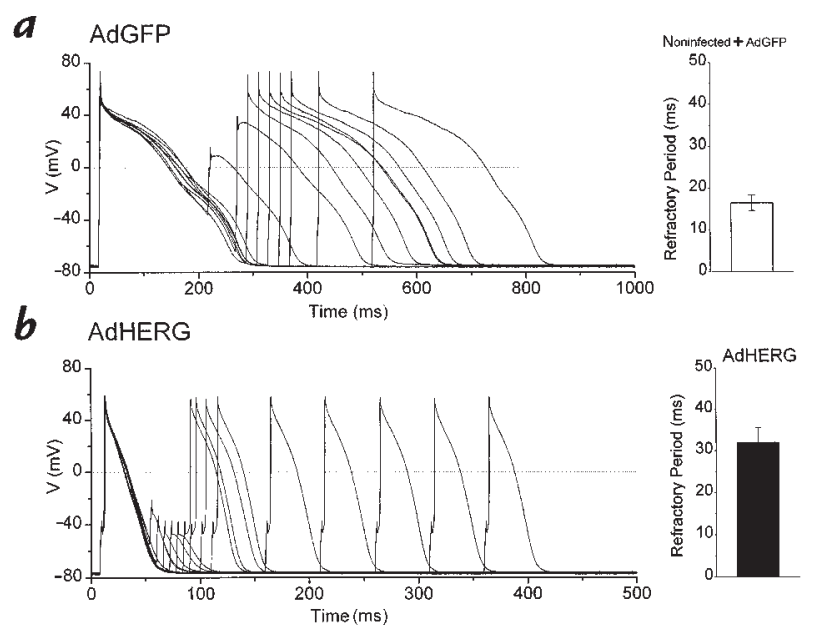

\section{Figure 8}

HERG overexpression increases refractory period. The refractory period was determined by interposing premature suprathreshold stimuli (115\% of threshold) at varying intervals during periods of continuous AP stimulation. (a) In noninfected and AdGFP-infected myocytes, a second AP could be elicited before final repolarization to resting potential was complete. (b) An obvious refractory period persisted in AdHERG-infected myocytes after the membrane voltage returned to resting potential. To quantify the refractory period independent of differences in APD between groups, refractory period was measured from the $\mathrm{APD}_{90}$ of the first $\mathrm{AP}$ to the next stimulus that elicited a second normal AP. The refractory period increased by $82 \%$ because of HERG overexpression $(n=4, P=0.02)$ compared with noninfected and AdGFP-infected controls $(n=3)$. 


\section{Acknowledgments}

This work was supported by the American Heart Association (Scientist Development Grant; to H.B. Nuss), the Markey Foundation (training grant; to D.C. Johns), and the Tanabe Seiyaku Co., Ltd. General laboratory support was provided by National Institutes of Health grant R37 HL-36957 (to E. Marbán).

1. Sanguinetti, M.C., and Jurkiewicz, N.K. 1990. Two components of cardiac delayed rectifier $\mathrm{K}^{+}$current. Differential sensitivity to block by class III antiarrhythmic agents. J. Gen. Physiol. 96:195-215.

2. Warmke, J.W., and Ganetzky, B. 1994. A family of potassium channel genes related to eag in Drosophila and mammals. Proc. Natl. Acad. Sci. USA. 91:3438-3442.

3. Trudeau, M.C., Warmke, J.W., Ganetzky, B., and Robertson, G.A. 1996. HERG sequence correction [letter]. Science. 272:1087.

4. Trudeau, M.C., Warmke, J.W., Ganetzky, B., and Robertson, G.A. 1995. $H E R G$, a human inward rectifier in the voltage-gated potassium channel family. Science. 269:92-95

5. Yang, W.P., et al. 1997. KvLQT1, a voltage-gated potassium channel responsible for human cardiac arrhythmias. Proc. Natl. Acad. Sci. USA. 94:4017-4021.

6. Wang, Q., et al. 1996. Positional cloning of a novel potassium channel gene: KVLQT1 mutations cause cardiac arrhythmias. Nat. Genet. 12:17-23

7. Romey, G., et al. 1997. Molecular mechanism and functional significance of the minK control of the KvLOT1 channel activity. J. Biol. Chem. 272:16713-16716.

8. Curran, M.E., et al. 1995. A molecular basis for cardiac arrhythmia: HERG mutations cause long QT syndrome. Cell. 80:795-803.

9. Tanaka, T., et al. 1997. Four novel KVLQT1 and four novel HERG mutations in familial long-QT syndrome. Circulation. 95:565-567.

10. Benson, D.W., et al. 1996. Missense mutation in the pore region of HERG causes familial long QT syndrome. Circulation. 93:1791-1795.

11. Satler, C.A., et al. 1996. Novel missense mutation in the cyclic nucleotidebinding domain of HERG causes long QT syndrome. Am. J. Med. Genet. 65:27-35

12. Satler, C.A., Vesely, M.R., Duggal, P., Ginsburg, G.S., and Beggs, A.H. 1998. Multiple different missense mutations in the pore region of $H E R G$ in patients with long QT syndrome. Hum. Genet. 102:265-272.

13. Honig, P.K., Woosley, R.L., Zamani, K., Conner, D.P., and Cantilena, L.R., Jr. 1992. Changes in the pharmacokinetics and electrocardiographic pharmacodynamics of terfenadine with concomitant administration of erythromycin. Clin. Pharmacol. Ther. 52:231-238.

14. Woosley, R.L., Chen, Y., Freiman, J.P., and Gillis, R.A. 1993. Mechanism of the cardiotoxic actions of terfenadine. JAMA. 269:1532-1536.

15. Wysowski, D.K., and Bacsanyi, J. 1996. Cisapride and fatal arrhythmia [letter]. N. Engl. J. Med. 335:290-291.

16. Bran, S., Murray, W.A., Hirsch, I.B., and Palmer, J.P. 1995. Long QT syndrome during high-dose cisapride. Arch. Intern. Med. 155:765-768

17. Suessbrich, H., Waldegger, S., Lang, F., and Busch, A.E. 1996. Blockade of HERG channels expressed in Xenopus oocytes by the histamine receptor antagonists terfenadine and astemizole. FEBS Lett. 385:77-80.

18. Drolet, B., Khalifa, M., Daleau, P., Hamelin, B.A., and Turgeon, J. 1998. Block of the rapid component of the delayed rectifier potassium current by the prokinetic agent cisapride underlies drug-related lengthening of the QT interval. Circulation. 97:204-210.

19. Li, G.R., Feng, J., Yue, L., Carrier, M., and Nattel, S. 1996. Evidence for two components of delayed rectifier $\mathrm{K}^{+}$current in human ventricular myocytes. Circ. Res. 78:689-696.

20. Noble, D., Varghese, A., Kohl, P., and Noble, P. 1998. Improved guineapig ventricular cell model incorporating a diadic space, $I_{\mathrm{Kr}}$ and $I_{\mathrm{Ks}}$, and length- and tension-dependent processes. Can. J. Cardiol. 14:123-134.

21. Zeng, J., Laurita, K.R., Rosenbaum, D.S., and Rudy, Y. 1995. Two components of the delayed rectifier $\mathrm{K}^{+}$current in ventricular myocytes of the guinea pig type. Theoretical formulation and their role in repolarization. Circ. Res. 77:140-152.

22. Priebe, L., and Beuckelmann, D.J. 1998. Simulation study of cellular electric properties in heart failure. Circ. Res. 82:1206-1223.

23. Silver, L.H., Hemwall, E.L., Marino, T.A., and Houser, S.R. 1983. Isolation and morphology of calcium-tolerant feline ventricular myocytes. Am. J. Physiol. 245:H891-H896.

24. Johns, D.C., et al. 1995. Adenovirus-mediated expression of a voltage-gated potassium channel in vitro (rat cardiac myocytes) and in vivo (rat liver). A novel strategy for modifying excitability. J. Clin. Invest. 96:1152-1158.

25. Rizzuto, R., Brini, M., Pizzo, P., Murgia, M., and Pozzan, T. 1995. Chimeric green fluorescent protein as a tool for visualizing subcellular organelles in living cells. Curr. Biol. 5:635-642.

26. Reichel, C., et al. 1996. Enhanced green fluorescence by the expression of an Aequorea victoria green fluorescent protein mutant in mono- and dicotyledonous plant cells. Proc. Natl. Acad. Sci. USA. 93:5888-5893.

27. Nuss, H.B., et al. 1996. Reversal of potassium channel deficiency in cells from failing hearts by adenoviral gene transfer: a prototype for gene therapy for disorders of cardiac excitability and contractility. Gene Ther. 3:900-912.

28. Hamill, O.P., Marty, A., Neher, E., Sakmann, B., and Sigworth, F.J. 1981. Improved patch-clamp techniques for high-resolution current recording from cells and cell-free membrane patches. Pflugers Arch. 391:85-100.

29. Mitcheson, J.S., Hancox, J.C., and Levi, A.J. 1996. Action potentials, ion channel currents and transverse tubule density in adult rabbit ventricular myocytes maintained for 6 days in cell culture. Pflugers Arch. 431:814-827.

30. Jurkiewicz, N.K., and Sanguinetti, M.C. 1993. Rate-dependent prolongation of cardiac action potentials by a methanesulfonanilide class III antiarrhythmic agent. Specific block of rapidly activating delayed rectifier $\mathrm{K}^{+}$current by dofetilide. Circ Res. 72:75-83.

31. Beatch, G.N., Davis, D.R., Laganiere, S., and Williams, B.A. 1996. Ratedependent effects of sematilide on ventricular monophasic action potential duration and delayed rectifier $\mathrm{K}^{+}$current in rabbits. J. Cardiovasc. Pharmacol. 28:618-630.

32. Patterson, E., Scherlag, B.J., Szabo, B., and Lazzara, R. 1997. Facilitation of epinephrine-induced afterdepolarizations by class III antiarrhythmic drugs. J. Electrocardiol. 30:217-224.

33. Jurkiewicz, N.K., Wang, J., Fermini, B., Sanguinetti, M.C., and Salata, J.J. 1996. Mechanism of action potential prolongation by RP 58866 and its active enantiomer, terikalant. Block of the rapidly activating delayed rectifier $\mathrm{K}^{+}$current, $I_{\mathrm{Kr} .}$. Circulation. 94:2938-2946.

34. Snyders, D.J., and Chaudhary, A. 1996. High affinity open channel block by dofetilide of HERG expressed in a human cell line. Mol. Pharmacol. 49:949-955

35. Sanguinetti, M.C., Jiang, C., Curran, M.E., and Keating, M.T. 1995. A mechanistic link between an inherited and an acquired cardiac arrhythmia: HERG encodes the $I_{\mathrm{Kr}}$ potassium channel. Cell. 81:299-307.

36. Yang, T., Snyders, D.J., and Roden, D.M. 1997. Rapid inactivation determines the rectification and $\left[\mathrm{K}^{+}\right]$o dependence of the rapid component of the delayed rectifier $\mathrm{K}^{+}$current in cardiac cells. Circ. Res. 80:782-789

37. Wang, S., Morales, M.J., Liu, S., Strauss, H.C., and Rasmusson, R.L. 1996. Time, voltage and ionic concentration dependence of rectification of HERG expressed in Xenopus oocytes. FEBS Lett. 389:167-173.

38. Wang, S., Morales, M.J., Liu, S., Strauss, H.C., and Rasmusson, R.L. 1997. Modulation of HERG affinity for E-4031 by $\left[\mathrm{K}^{+}\right]$o and C-type inactivation. FEBS Lett. 417:43-47.

39. Zhou, Z., et al. 1998. Properties of HERG channels stably expressed in HEK 293 cells studied at physiological temperature. Biophys. J. $74: 230-241$

40. Beuckelmann, D.J., Nabauer, M., and Erdmann, E. 1993. Alterations of $\mathrm{K}^{+}$currents in isolated human ventricular myocytes from patients with terminal heart failure. Circ. Res. 73:379-385

41. Liu, S., Rasmusson, R.L., Campbell, D.L., Wang, S., and Strauss, H.C. 1996. Activation and inactivation kinetics of an E-4031-sensitive current from single ferret atrial myocytes. Biophys. J. 70:2704-2715.

42. Follmer, C.H., and Colatsky, T.J. 1990. Block of delayed rectifier potassium current, $I_{\mathrm{K}}$, by flecainide and E-4031 in cat ventricular myocytes. Circulation. 82:289-293.

43. Nuss, H.B., Kääb, S., Kass, D.A., Tomaselli, G.F., and Marbán, E. 1995. Increased susceptibility to arrhythmogenic early afterdepolarizations and oscillatory prepotentials in failing canine ventricular myocytes. Circulation. 92:I-434 (Abstr.)

44. Aizawa, Y., Uchiyama, H., Yamaura, M., Nakayama, T., and Arita, M. 1998. Effects of the ATP-sensitive K channel opener nicorandil on the QT interval and the effective refractory period in patients with congenital long QT syndrome. Investigator Group for K-Channel Openers and Arrhythmias. J. Electrocardiol. 31:117-123.

45. Miller, C. 1996. The inconstancy of the human heart. Nature. 379:767-768.

46. Salata, J.J., et al. 1996. $I_{\mathrm{K}}$ of rabbit ventricle is composed of two currents: evidence for $I_{\mathrm{Ks}}$. Am. J. Physiol. 271:H2477-H2489.

47. Rozanski, G.J., Xu, Z., Whitney, R.T., Murakami, H., and Zucker, I.H. 1997. Electrophysiology of rabbit ventricular myocytes following sustained rapid ventricular pacing. J. Mol. Cell. Cardiol. 29:721-732.

48. Clay, J.R., Ogbaghebriel, A., Paquette, T., Sasyniuk, B.I., and Shrier, A. 1995. A quantitative description of the E-4031-sensitive repolarization current in rabbit ventricular myocytes. Biophys. J. 69:1830-1837.

49. McDonald, T.V., et al. 1997. A minK-HERG complex regulates the cardiac potassium current $I_{\mathrm{Kr}}$. Nature. 388:289-292. 